\title{
Vida e obra de uma menina nada comportada: \\ Pagu e o Suplemento Literário do Diário de $S$. Paulo
}

\begin{abstract}
Heloisa Pontes ${ }^{* *}$
Polêmica, irreverente, emancipada. Tais são os qualificativos que mais fortemente marcaram o imaginário construído em torno da figura pública de Patrícia Galvão (19101962). Ou simplesmente Pagu. Apelido que recebeu aos 18 anos do poeta Raul Bopp e com o qual se tornou conhecida nos anos de 1920 quando, ainda colegial, fazia às vezes de mascote do modernismo paulista e de "boneca" ${ }^{1}$ do casal Tarsila e Oswald de Andrade. Essa fulgurante inserção no universo de sociabilidade da vanguarda da época aconteceu antes do romance avassalador de Patrícia com Oswald, do nascimento, em 1930, do filho de ambos (Rudá de Andrade) e da entrada deles no Partido Comunista em 1931. A isso se sucedeu uma série de acontecimentos que marcariam a vida de Patrícia Galvão no decênio de 1930: a mudança para o Rio de Janeiro em 1932, a publicação no ano seguinte de Parque industrial, tido como o primeiro romance

\footnotetext{
"Resenhas dos livros: Neves, Juliana. Geraldo Ferraz e Patrícia Galvão: a experiência literária do Suplemento Literário do Diário de S. Paulo, nos anos 40. São Paulo, Annablume/Fapesp, 2005; e FERRAZ, Geraldo Galvão. (org.) Paixão Pagu: a autobiografia precoce de Patrícia Galvão, Rio de Janeiro, Agir, 2005.

** Professora do departamento de Antropologia do Instituto de Filosofia e Ciências Humanas e pesquisadora do Núcleo de Estudos de Gênero Pagu, ambos na Unicamp. helopontes@uol.com.br

1 A expressão é do artista plástico Flávio de Carvalho e encontra-se reproduzida no "Roteiro de uma vida-obra". In: CAMPOS, Augusto de. (org.) Pagu: vida-obra. São Paulo, Brasiliense, 1982, p.320.
}

cadernos pagu (26), janeiro-junho de 2006: pp.431-441. 
Vida e obra de uma menina nada comportada

proletário brasileiro, a viagem pelo mundo em 1934 (quando estréia como repórter), os meses que morou em Paris (sem Oswald e o filho) onde foi presa como militante comunista estrangeira. Repatriada, voltaria ao Brasil em 1934 e, por duas vezes, em 1935 e 1938, seria presa novamente. Libertada em julho de 1940, depauperada e magérrima, Pagu se casou com Geraldo Ferraz (1905-1979), com quem viveu até o fim da sua vida e com quem entrou pra valer na cena cultural, ligando-se ao periódico Vanguarda Socialista, em 1945, e iniciando, no ano seguinte, a sua colaboração regular no Suplemento literário do Diário de $S$. Paulo.

Do casamento de ambos nasceria Geraldo Galvão Ferraz, o segundo filho de Pagu, jornalista como os pais e o principal responsável pela publicação da autobiografia precoce de sua mãe. A ele, ao meio irmão, Rudá de Andrade, e à jovem socióloga Juliana Neves devemos um novo olhar sobre o mito construído em torno de Pagu. Aos dois primeiros pela coragem e empenho na publicação da longa carta que a mãe de ambos escreveu para Ferraz em 1940 e que só agora, sessenta e seis anos depois de ser redigida para ser lida na chave da entrega amorosa e não no registro da palavra impressa, veio a público sob o título Paixão Pagu: a autobiografia precoce de Patrícia Galvão, numa edição caprichada, ricamente ilustrada com fotografias de Pagu e de pessoas ligadas a ela. Juliana Neves, a terceira dessa trinca, é a autora do livro Geraldo Ferraz e Patrícia Galvão: a experiência literária do Suplemento Literário do Diário de S. Paulo, originalmente uma dissertação de mestrado.

Concebidos com propósitos distintos e escritos em tempos diversos, esses dois livros apresentam uma Pagu mais complexa do que a visão dominante que vem sendo construída sobre ela desde os anos de 1980, quando depois de um período de relativo silêncio, foi súbita e acertadamente recuperada pela pena irreverente do poeta concretista Augusto de Campos. O livro Pagu: vida e obra, publicado em 1982 pela Brasiliense (uma das editoras de maior prestígio na época), trouxe Patrícia Galvão de 
volta à cena cultural e política. Figura emblemática do feminismo que se organizava na época, símbolo da mulher emancipada $e$ libertária, escritora concretista "avant la lettre", Patrícia Galvão virou uma espécie de ícone capaz de atender e preencher demandas e conteúdos diversos. Sua fama, amplificada pelos meios de comunicação, pela televisão que a transformou em heroína de mini-série, pelos filmes de Norma Benguell e de Joaquim Pedro de Andrade, chegou a lugares inesperados. Pagu "se multiplicou - sublinha o filho, Geraldo Galvão Ferraz - em balés, espetáculos teatrais. Emprestou o nome a centros culturais, livrarias e até butiques". ${ }^{2}$

Em virtude da fama crescente era previsível que uma parte da história - e da personalidade que lhe conferiu tônus - se perdesse para dar lugar a enredos edulcorantes, afeitos, enquanto forma narrativa, às construções míticas que teimam em proliferar nos tempos modernos. Da menina levada à mulher liberada foi um passo. Dado menos por ela, na condição de protagonista, e mais pelos intérpretes que a tomaram como heroína das suas histórias. Não que ela não fosse as duas coisas, isto é, heroína e protagonista. E sim que não fosse tanto quanto alardeado, como prova a longa carta que ela escreveu para Geraldo Ferraz. Pagu tinha então 30 anos e vivia o auge do sofrimento provocado pelos quatro anos passados na prisão durante o regime ditatorial do Estado Novo. Redigida com furor e paixão, a carta é um acerto de contas com o passado, a família, o casamento com Oswald de Andrade, a opção pela militância política nos quadros do Partido Comunista, tida naquela altura por ela como completamente equivocada. Mas é também promessa de futuro, de uma vida que se queria partilhada por inteiro e sem resquícios das convenções que rondavam os casamentos na época, com o homem que escolhera para ser o seu segundo marido.

2 FerRAz, G. G. A vida dentro de uma pasta preta. In: Paixão Pagu... Op. cit., p.13. 
Vida e obra de uma menina nada comportada

Várias são as leituras possíveis dessa "autobiografia precoce" escrita por uma mulher marcada pelo sofrimento que, quando menina, se via como uma "moleca impossível" e que, "sentido-se à margem das outras vidas", esperava a sua "oportunidade de evasão" (p.57). Tal oportunidade veio antes do seu ingresso no círculo de sociabilidade dos modernistas. Aos doze anos e em meio a um romance sem alarde com Olympio Guilherme, ela consumou o primeiro "fato consciente" de sua vida: a "entrega do próprio corpo". Entrega no sentido mais abrangente do termo, beirando a um ato de dádiva de si e não de busca pelo prazer sexual.

A um só tempo "acima" e "abaixo" da experiência erótica, o amor não se realizou como experiência corporal plena com o primeiro namorado, de quem engravidou e abortou aos 14 anos. Tampouco com Oswald de Andrade, por quem nutria sentimentos contraditórios de admiração, repulsa e atração. A ponto de afirmar categoricamente que nunca o amou, nem no início do romance quando, para não "dar importância ao ato sexual", entregou-se a ele "com indiferença, talvez um pouco amarga". O que os ligava era uma curiosidade imensa, o prazer das leituras, as conversas intermináveis, a opção de ambos pela militância política nos quadros do Partido Comunista, a gratidão pela "brutalidade da franqueza". Nas palavras de Pagu, "o meu agradecimento vai para o homem que nunca me ofendeu com a piedade", nem lhe omitiu as aventuras extraconjugais - que não foram poucas $e$ ocorreram inclusive no período de suas duas gestações: uma delas abortada involuntariamente, a outra completada com o nascimento de Rudá.

A maternidade, longe apaziguá-la, é vivida como uma experiência bastante tumultuada. $\mathrm{O}$ amor pelo filho sujeita-se aos desígnios da luta política e da agenda do Partido Comunista, e é conjugado com uma incondicionalidade plena de ambivalências, na contramão das convenções maternas da época. Várias foram as vezes em que Rudá ficou sob os cuidados de Oswald enquanto Patrícia Galvão, envolvida até a raiz dos cabelos com a militância, 
se ausentava de casa por longos períodos. Primeiro em Santos, depois no Rio de Janeiro para onde se mudou em 1932, a mando do Partido com a finalidade de que ela conhecesse por dentro as vicissitudes da vida proletária e firmasse a atuação política em patamar mais sólido.

Não é o caso aqui de registrar o itinerário das mudanças, das viagens e das ausências de Pagu. O leitor terá o gosto de acompanhar por si o registro dessa vida atribulada. O que me parece importante destacar é que se ela passa ao largo das convenções então dominantes no plano da experiência amorosa $e$ da maternidade, nem por isso está isenta delas. Embora veladas, elas se deixam apanhar num lugar diverso do esperado para uma mulher que fez fama e nome como símbolo da irreverência e da emancipação no domínio sexual e dos costumes. Onde? Na busca intensa e deliberada de Pagu por uma transcendência de si e na entrega baseada no sacrifício. Nessa estrutura de sentimentos edificantes, que por tantos séculos pautou a vida de santos e das mulheres reclusas em conventos, encontra-se o núcleo denso que amarra as pontas partidas da experiência amorosa, da maternidade e da militância de Pagu. Descentrada em relação à matriz religiosa de onde derivava força e sentido, uma vez que Patrícia Galvão era e permaneceu agnóstica, ela migrou para o terreno profano da política. Mas o que se perdeu no plano do sagrado, ganhou, no quadro mental dos adeptos do Partido Comunista na época, um sentido renovado de abnegação de si em prol de uma causa maior, dirigida a dirimir as injustiças de todo o tipo que no entender dos militantes impediam a realização plena da humanidade. Luta de classes e luta política conjugam-se na militância de Pagu com uma obediência estrita e restrita às diretrizes do Partido, conformando uma vivência de gênero no registro da sujeição e do apagamento de si.

Vista à luz das experiências políticas contemporâneas, marcadas em larga medida pela desconfiança em relação à possibilidade de qualquer "pureza" nesse campo inclusive e, sobretudo, no domínio nebuloso das clivagens entre as 
Vida e obra de uma menina nada comportada

"esquerdas", impressiona (e muito) que Pagu, aparentemente tão irreverente como mulher, pudesse ter se curvado dessa maneira aos ditames dos dirigentes do Partido Comunista. Os quais incluíam chantagens de ordem variada e até mesmo o uso da sedução feminina como arma legítima na luta política. Tendo se prestado a isso em algumas ocasiões, Patrícia Galvão faz da carta a Ferraz uma instância de autopurgação e expiação. E à medida que o relato sofrido e apaixonado vai tomando corpo, mais e mais evidentes parecem ser as ligações entre a sexualidade "seqüestrada" (por ela mesma), a maternidade partida e a militância como exercício de transcendência baseada no autosacrifício. Dessa figuração sobressai uma mulher tumultuada, a deixar na sombra a Pagu lânguida dos anos de 1920, de olhos enevoados e tão misteriosos quanto os de Capitu, de cabelos fartos e boca bem delineada pelo batom vermelho, que marcou a iconografia do modernismo paulista e o imaginário social em torno dela.

Entrega e submissão são os dois eixos centrais da trajetória de Pagu até o final dos anos de 1930. E é justamente essa fruição no sofrimento que parece conferir sentido à maneira como ela vive o amor, a militância política $e$ a maternidade, para absoluto espanto do leitor embalado pela visão libertária que se construiu sobre ela a partir dos anos de 1980. O incômodo inicial suscitado pela leitura dessa "autobiografia precoce" tem muito de anacronismo. Da minha parte, evidentemente, que não escapei da armadilha de ler o passado à luz das questões e desafios postos pelo presente. Como é possível que tudo tenha se passado dessa maneira com uma mulher que sob muitos aspectos esteve à frente do seu tempo, é a questão que persiste ao final da leitura. Até que mudando o registro da indagação fui me dando conta do "ovo de Colombo": a Patrícia Galvão que se tornou Pagu foi de uma certa maneira "inventada" nas últimas décadas para driblar as ciladas do gênero e seus constrangimentos sociais. Algo não muito distinto do que aconteceu com Leila Diniz ou com a criação de 
uma genealogia intelectual e artística entre o concretismo, o tropicalismo e a antropofagia de Oswald de Andrade.

Domado o anacronismo, desenha-se uma Pagu mais complexa e torturada, que parece não medir esforços para fazer o que the parece certo no plano familiar, amoroso, político $e$ profissional. Eis aí o saldo maior da leitura da longa carta endereçada a Ferraz que a guardou por tantos anos até que temendo a morte, decidiu doá-la ao filho. Graças à herança partilhada por ele, temos hoje a possibilidade de revisitar Patrícia Galvão e seu legado sob novos enfoques. Sobretudo quando cotejamos a leitura dessa carta com o livro de Juliana Neves, Geraldo Ferraz e Patrícia Galvão: a experiência literária do Suplemento Literário do Diário de S. Paulo, publicado também em 2005.

Estudo original sobre a importância desse suplemento, que pela primeira vez recebe uma análise detalhada, o trabalho de Juliana oferece ainda um contexto bem armado para situarmos a transferência de energia e de libido observada na trajetória de Pagu. Com a mesma intensidade que vivera a militância política nos anos de 1930, Pagu se lançaria de corpo e alma na militância cultural, na década seguinte. Tal deslocamento de energias não seu deu no vazio universalista das abstrações piscologizantes. Mas fincou-se no solo intelectual e cultural da cidade de São Paulo dos anos de 1940, como mostra o livro de Juliana Neves.

Criado em 1946 por Geraldo Ferraz e Patrícia Galvão, o Suplemento Literário do Diário de S.Paulo é a primeira experiência desse tipo de empreendimento no âmbito do jornalismo paulista, tendo precedido o famoso Suplemento Literário de $O$ Estado de S.Paulo - que reuniu em novas bases os integrantes do Grupo Clima, responsáveis pela edição da revista Clima, entre 1941 e 1944. Lançado em 1956, esse último suplemento teve vida longa e já mereceu análises detidas por parte dos pesquisadores interessados em adensar a história cultural e intelectual brasileira. Situação bastante distinta da que se verificava com o empreendimento jornalístico do casal Geraldo 
Vida e obra de uma menina nada comportada

Ferraz e Patrícia Galvão, que durou apenas dois anos. O livro de Juliana Neves vem, assim, preencher uma lacuna, que há tempos reclamava um estudo dessa natureza.

Além do recenseamento minucioso da produção veiculada nesse suplemento e de seus colaboradores mais importantes, a análise de Juliana contribui para alargar a nossa compreensão do campo das artes, da literatura e da cultura em São Paulo. Em meio ao processo de metropolização que se verifica na capital paulista nas décadas de 1940 e 50, assiste-se também, como mostra a autora, o agenciamento de novas articulações entre o jornalismo $e$ as manifestações de ponta no âmbito da cultura erudita da cidade.

Nesse ir e vir entre a imprensa e a cena cultural mais ampla reside um dos méritos do livro. $\mathrm{O}$ outro se encontra na acertada opção de Juliana pela reconstrução da experiência desse suplemento à luz da parceria amorosa e de trabalho estabelecida entre Ferraz e Galvão. Não era a primeira vez que eles faziam um empreendimento conjunto. Em 1945, quando participaram da redação do jornal $A$ Vanguarda Socialista, fundado por Mário Pedrosa e secretariado por Ferraz, publicaram também o romance que escreveram a quatro mãos, $A$ famosa revista. Mas foi no Suplemento que o empenho de ambos em divulgar o que de mais importante estava acontecendo na cena cultural, literária e artística da época, se concretizou em base mais profissional. Empenhado na formação de um público leitor, o casal reveste o Suplemento de uma explícita função pedagógica e didática. Na concepção de Ferraz, integralmente partilhada por Patrícia Galvão, o objetivo central do empreendimento jornalístico capitaneado por eles era o de "formar" e "inquietar".

Não parece aleatório que ambos os protagonistas dessas páginas tenham sido eles mesmos autodidatas. Diferentemente, por exemplo, dos criadores e principais colaboradores do Suplemento Literário do jornal $O$ Estado de S. Paulo - iniciado em 1956, dez anos depois do lançamento do suplemento analisado por Juliana Neves - que tinham uma formação 
universitária, Ferraz e Patrícia Galvão nunca freqüentaram a universidade. Entre outras razões, pela ausência de condições materiais, no caso de Ferraz, que teve uma infância amarga $e$ difícil, marcada pela orfandade precoce (o pai e a mãe morreram de tuberculose quando ele tinha dez anos). Ou sociais, no caso de Pagu, cujos horizontes familiares, em termos do esperado para a formação de uma moça, não ultrapassavam a conclusão da Escola Normal. Coisa que ela de fato fez em 1928, aos dezoito anos de idade.

Ainda menino Feraz já trabalhava para se sustentar. Começou a vida profissional aos doze anos na Tipografia Condor, onde descobriu, em suas palavras, a "vocação" para a atividade intelectual e jornalística. ${ }^{3}$ Em 1927 entrou no mundo jornalístico, primeiro como revisor no Jornal do Comércio e logo depois no Diário da Noite. No ano seguinte virou repórter no vespertino dos Diários Associados de Assis Chateaubriand. Ali escreveu seu primeiro artigo como crítico de arte.

Ferraz foi o primeiro crítico de arte modernista a atuar profissionalmente na imprensa paulista. Antes dele, Oswald de Andrade já havia escrito sobre o assunto, mas de forma pouco sistemática. O interesse de Ferraz pelas artes plásticas manifestouse no ano de 1927, em decorrência da relação que estabelecera com o artista e arquiteto Flávio de Carvalho, e da leitura da Revista do Ocidente, dirigida por Ortega y Gasset. Dada a inexistência no período de um Museu de Arte, aliada no seu caso à ausência de uma escolaridade formal, ele teve que substituir a experiência direta das obras pelo contato com sua reprodução na bibliografia que podia adquirir nas livrarias ou consultar nas bibliotecas. Até 1924, a única exposição que vira foi a de Lasar Segall.

Cinco anos depois, bem mais informado sobre a história da arte e sobre as experiências artísticas de vanguarda, em razão das

3 Citação retirada do livro de memórias de FERRAz, Geraldo. Depois de Tudo. Rio de Janeiro, Paz e Terra, 1983. 
Vida e obra de uma menina nada comportada

leituras que vinha fazendo sobre o tema, foi apresentado a Tarsila do Amaral e Oswald de Andrade. O ano era 1929 e graças à relação que estabeleceu com o casal "Tarsi-Oswald", entrou em contato com várias personalidades, próximas ou integrantes, do modernismo paulista, e viabilizou o início de sua atuação como crítico de arte. Ao longo dos anos de 1930 e principalmente na década de 1940, já casado com Patrícia Galvão e mergulhado na rotina diária do jornalismo, Ferraz dedicou-se com afinco à crítica de arte. Como jornalista profissional, encontrou espaço na imprensa para veicular as suas opiniões $e$ avaliaçóes sobre a pintura não acadêmica da época. Paralelamente, participou também da organização de eventos importantes ligados às artes plásticas, prefaciou catálogos de exposições, entrevistou diversos pintores.

$\mathrm{Na}$ ausência de publicações e críticos especializados, a crítica de arte no período era veiculada basicamente na imprensa diária e, secundariamente, nas revistas culturais. O jornal era o órgão central para os críticos divulgarem suas opiniões e análises sobre as artes plásticas. Os livros que editavam nesta área eram, quase sempre, coletâneas de artigos publicados primeiro na imprensa. Neste contexto de baixa institucionalização da atividade intelectual, onde o diploma de advogado conferia como que um passaporte imediato para o exercício de atividades várias no campo cultural e jornalístico, não era necessário ainda deter um conhecimento amplo e simultaneamente específico, para habilitarse à crítica de arte. Este era adquirido no decorrer dos itinerários dos críticos, como prova a trajetória de Geraldo Ferraz.

Enquanto nas páginas do Suplemento literário do Diário de S.Paulo ele se dedicou à crítica de arte e à divulgação da arquitetura moderna, Patrícia Galvão fez crítica literária. Juntos contribuíram para calçar essas duas modalidades de intervenção em bases jornalísticas mais sólidas.

Pioneiros na criação de um suplemento cultural de vida curta - fechado em 1948 por ordem e capricho do seu patrocinador, Assis Chateaubriand, o magnata do jornalismo 
brasileiro na época - eles construíram uma parceria amorosa e de trabalho que dá o que pensar, como bem mostra Juliana Neves. Essa parceria aponta nas palavras da autora, para o

trânsito de mão dupla de um casal de jornalistasintelectuais, representantes da vanguarda, que procuram fora das rotinas das redações reconhecimento no meio cultural, mas que, de modo contraditório, inserem-se nele devido em grande medida às suas atividades nos jornais. (p.22)

Iniciei esta resenha afirmando que a leitura em conjunto dos livros em pauta obriga a uma revisão do mito construído em torno de Pagu. Não com qualquer intuito de diminuir a sua importância na cena cultural e política, mas de aquilatá-la a partir de interpretações mais complexas, com atenção redobrada para a captação de dimensões menos alardeadas da sua personalidade. O livro de Juliana Neves oferece nesse sentido um contexto informado para situar a atuação empenhada de Pagu no âmbito da política cultural. E ainda que o trabalho não se restrinja a esse ponto - visto que o objetivo mais amplo da autora é a análise das intersecções entre a imprensa, a literatura e as artes -, ele dá a ver, por um olhar de esguelha, uma outra face de Pagu. Cotejado com a "autobiografia precoce" publicada por iniciativa de Geraldo Galvão Ferraz, o trabalho de Juliana deixa entrever a tentativa de Pagu para "domar" algumas das dimensões mais tumultuadas e torturadas de sua personalidade através da aplicação concentrada na rotina jornalística. Encerrado o Suplemento em 1948, ela tentaria o suicídio no ano seguinte. A relação entre os dois fatos não é em absoluto de causa e efeito, mas diz alguma coisa sobre as tensões que atravessam a vida de Pagu e sobre a maneira como ela se joga integralmente no trabalho para aplacá-las. Tais são algumas das pistas abertas pela leitura dos dois livros resenhados que valeriam a pena perseguir em estudos futuros. 